\title{
CURSO DE PEDAGOGIA NO BRASIL: ALGUMAS DISCUSSÕES SOBRE AS POLÍTICAS DE FORMAÇÃO
}

Pedagogy course in Brazil: some discussions about training policies

Curso de pedagogía en Brasil: algunas discusiones sobre politicas de formación

Miro Souza Almeida*

Maria Eneida da Silva**

Andréa Kochhann***

https://doi.org/10.38117/2675-181X.formov2021.v3i1n5.152-164.

\section{Resumo}

Este artigo objetiva discutir algumas concepções críticas e emancipatórias para analisar as atuais DCN e BNC para a Formação Inicial de Professores instituídas pela Resolução CNE/CP n. 02/2019. A partir da questão "quais são as implicações dessa resolução para o curso de Pedagogia?", fundamentamo-nos no materialismo histórico dialético com o referencial teórico de Marx (1999), Gramsci (2001), Lukács (2018), Saviani (2019) etc. e também na metodologia de investigação bibliográfica e em dados qualitativos, pois esses recursos atendem a proposta delimitada no estudo Esse estudo é valorizar a unidade teoria/ prática que fundamenta tanto a didática quanto os valores inerentes ao exercício pleno da docência do pedagogo no país. A política neoliberal conservadora reforça a concepção de educação pautada na eficiência do capital e, com anuência do CNE e MEC, promove ataques tanto na formação inicial dos futuros profissionais da educação básica e do pedagogo de nível superior

Palavras-chave: Materialismo histórico; Progressistas; Neoliberais; Diretrizes e BNCC Formação.

\section{Abstract}

This article aims to discuss some critical and emancipatory conceptions to analyze the current $\mathrm{DCN}$ and BNC for the Initial Teacher Training instituted by Resolution CNE/CP $\mathrm{n}$. 
$02 / 2019$. Based on the question "what are the implications of this resolution for the Pedagogy course?", We are based on dialectical historical materialism with the theoretical framework of Marx (1999), Gramsci (2001), Lukács (2018), Saviani (2019) etc. and also in the bibliographic research methodology and qualitative data, as these resources meet the proposal outlined in the study. This study is to value the theory / practice unit that underlies both didactics and the values inherent to the full exercise of teaching by the pedagogue in the country. The conservative neoliberal policy reinforces the concept of education based on the efficiency of capital and, with the consent of the CNE and MEC, promotes attacks both in the initial training of future professionals in basic education and in higher education.

Keywords: Historical materialism; Progressive; Neoliberals; Guidelines and BNCC Training.

\section{Resumen}

Este artículo tiene como objetivo discutir algunas concepciones críticas y emancipadoras para analizar el DCN y BNC actuales para la Formación Inicial Docente instituida por la Resolución CNE / CP n. 02/2019. A partir de la pregunta "¿cuáles son las implicaciones de esta resolución para el curso de Pedagogía?”, Nos basamos en el materialismo histórico dialéctico con el marco teórico de Marx (1999), Gramsci (2001), Lukács (2018), Saviani (2019) etc. y también en la metodología de la investigación bibliográfica y los datos cualitativos, ya que estos recursos cumplen con la propuesta planteada en el estudio. Este estudio tiene como objetivo valorar la unidad teoría / práctica que subyace tanto a la didáctica como a los valores inherentes al ejercicio pleno de la docencia por parte del pedagogo en el país. La política conservadora neoliberal refuerza el concepto de educación basada en la eficiencia del capital y, con el consentimiento del CNE y el MEC, promueve ataques tanto en la formación inicial de los futuros profesionales de la educación básica como en la educación superior.

Palabras clave: Materialismo histórico; Progresivo; neoliberales; Directrices y Formación BNCC.

\section{Introdução}

Este estudo tem por objetivo discutir algumas concepções críticas e emancipatórias para analisar as atuais Diretrizes Curriculares Nacionais - DCN e a Base Nacional Comum para a Formação Inicial de Professores BNC-Formação instituídas pela Resolução CNE/CP n. 02/2019 (BRASIL, 2019). Para responder à questão-problema “quais são as implicações dessa resolução para o curso de Pedagogia?", fundamentamonos no materialismo histórico-dialético com o referencial teórico de Marx (1999), 
Gramsci (2001), Lukács (2018), Saviani (2019) etc. e, também, na metodologia de investigação bibliográfica e em dados qualitativos, pois esses recursos atendem à proposta delimitada no estudo.

Assim, temos como objetivo discutir a valorização da unidade teoria/prática que fundamenta a práxis tanto a didática quanto os valores inerentes ao exercício pleno da docência do pedagogo no país, em contraponto com a atual política educacional eivada pela ideologia neoliberal que se reflete nas entrelinhas da Resolução CNE/CP n. 02/2019. Nesse sentido (Marx,1985) contesta essa concepção quando explícita que "a separação do trabalhador de sua existência objetiva é a base sobre a qual se acentua a reestruturação do capitalismo contemporâneo por meio do controle legal amparado na instituição de normas". Portanto, é inconcebível uma reforma educacional sem levar em consideração a transformação no contexto social, histórico oriundas do trabalho do pedagogo como ser ontológico (MÉSZÁROS, 2008).

Partimos, então, da possibilidade de tecer um contraponto referendado na história do Curso de Pedagogia no Brasil, desde a Resolução CNE/CP n. 2, de $1^{\circ}$ de julho de 2015 (BRASIL, 2015), a partir da organização e sistematização de discussões por especialistas da área, na constituição de epistemologias acerca da polêmica fundamentada no marco legal da Resolução n. 02/2019 (BRASIL, 2019). Destacamos duas tendências pedagógicas no país que representam não só a contradição, mas também a mediação dos processos em disputas de poder no âmbito político da educação, a saber: a Pedagogia Histórico-crítica e o neotecnicismo. A primeira tem o respaldo de uma concepção de educação progressista, ou seja, de uma formação humana que está em consonância com a formação integral do sujeito, para o qual a cultura, a arte, a filosofia, a economia e a política são elementos de conscientização e, portanto, contribui para o sentimento de pertencimento à coletividade e anseia por uma sociedade justa, igualitária, sem estratificação social.

Já o neotecnicismo vem ao encontro da proposta neoliberal que justifica a educação para atender aos interesses do capital, isto é, propõe a homogeneização do currículo e a fragmentação do processo de ensino-aprendizagem por meio da padronização da avaliação (avalições em carga escala). Essa proposição acentua o "apartheid social" que se estrutura na reprodução de valores que fundamentam uma concepção de mundo baseada na sociedade mercantil. Nesse sentido, é de extrema relevância a análise crítica das Diretrizes Nacionais para a Formação Inicial de Professores da Educação Básica e também da Base Nacional Comum para a Formação Inicial, instituídas pela Resolução n. 02/2019 (BRASIL, 2019), que se ancoram nessa visão neotecnicista de educação, desencadeando, cada vez mais, a precarização e 
intensificação do trabalho docente, baixa remuneração, a fragmentação da formação inicial e, consequentemente, da formação continuada.

Para o alcance dos objetivos propostos, o texto está estruturado em três seções, intituladas: "A disputa intelectual e histórica do curso de Pedagogia no Brasil"; "A rigidez política e ideológica implícita na Resolução n. 02/2019"; e "Aparência e essência pedagógica que constituem a Resolução n. 2/2019”. Assim, diante das mudanças postas em marcha pela referida resolução, esperamos contribuir com o debate sobre o que subjaz às novas Diretrizes Curriculares Nacionais - DCN e a Base Nacional Comum para a Formação Inicial de Professores BNC-Formação.

\section{A disputa intelectual e histórica do curso de Pedagogia no Brasil}

Historicamente, a educação brasileira sempre esteve e está na mira dos holofotes políticos. Com o passar de décadas, o curso de Pedagogia, que tem na sua essência o potencial ontológico de formação para o exercício da docência na perspectiva da práxis, esbarra nos interesses divergentes das classes sociais que estão no campo da disputa política, ideológica e econômica. São notórios os reflexos no âmbito educacional oriundos do capitalismo financista internacional enquanto sistema social de acumulação de capital e exploração da mais valia que desencadeia políticas de atuação e controle de grande parte da infraestrutura e superestrutura que constitui a sociedade civil ${ }^{1}$ no país.

Nesse sentido, Evangelista, Seki e Souza (2019, p. 150) destacam que são presenciadas

[...] negociações ininterruptas entre o Estado brasileiro e Organizações Multilaterais (OM), como o Banco Mundial (BM), a Unesco, a Organização Mundial do Comércio (OMC), nas quais as últimas viram suas posições ideológicas e econômicas em boa parte incorporadas nas políticas educacionais.

Esses acordos têm reflexos diretos nas políticas de formação de professores seja inicial seja continuada. Um exemplo que evidencia a mudança no enfoque da educação é a supremacia da concepção de formação em serviço, ou seja, valoriza-se a formação do professor numa perspectiva gnosiológico, desconsiderando na política de formação os aspectos social, histórico, cultural e econômico do ser social professor. Ademais, tal como assinala Netto $(2015$, p. 80) “[...] nisto se evidencia a contraposição entre o materialismo

\footnotetext{
1 O termo gramsciano "sociedade civil" se refere aos segmentos da sociedade que representam os trabalhadores e trabalhadoras, bem como as entidades organizadas do campo progressista.
} 
e o idealismo, porque não existe o primado abstrato da consciência sobre o ser, pelo contrário, o fundamento é ontológico e nesse aspecto, o ponto de partida é o ser social".

Esse conjunto de elementos históricos, políticos, sociais e culturais impacta diretamente no desenvolvimento da concepção progressista de educação pública, cuja ideia é assegurar a igualdade de condições para todos, elevando o nível de consciência das massas. Desde a Constituição de 1988 (BRASIL, 1988), está garantido o direito à educação a todos e todas enquanto dever do Estado e da família, requerendo da sociedade a colaboração para tal garantia. Assim, diversos movimentos de educadores, principalmente nos anos de 1980 e 1990, surgiram para pesquisar e formular princípios e diretrizes para a educação básica e superior do Brasil, bem como para estruturar a formação inicial e continuada de professores.

Após longos anos de luta por uma formação de professores que estivesse ancorada na concepção socio-histórica, crítica e emancipatória de formação, foi sancionada a Resolução CNE/CP n. 2/2015 que instituiu as Diretrizes Curriculares Nacionais para o Curso de Graduação em Pedagogia, licenciatura (BRASIL, 2015). Naquele contexto histórico, político, social e econômico, houve momentos de fala e de escuta por parte do Ministério da Educação - MEC e do Conselho Nacional de Educação - CNE quando se estabeleceu o diálogo com entidades nacionais de defesa da educação e da formação de professores, sindicatos e outras organizações da sociedade civil, a fim de se construir um consenso. A docência foi evidenciada - conjuntamente com a ideia de se constituir uma identidade para o pedagogo (a) - como princípio norteador, agregando a possibilidade de efetivação e aquisição de conhecimentos pedagógicos em diferentes segmentos e espaços educativos, tendo a gestão e a pesquisa como elementos estruturantes.

No entanto, a partir do golpe de 2016, deu-se início ao desmonte da educação no país com mudanças consideráveis na composição do CNE e do próprio MEC e a redação da $3^{a}$ versão da Base Nacional Comum Curricular - BNCC (BRASIL, 2017) que, distante das versões anteriores oriundas de mobilizações e discussões nas escolas e seminários ocorridos nos 26 estados e no Distrito Federal, apresenta um novo paradigma, desconsiderando a diversidade escolar, cultural e humana do país por meio da padronização curricular pautada na eficiência sob a ótica empresarial. Para o completar a nefasta proposta de desmonte iniciada pela BNCC, é instituída a Resolução CNE/CP n. 02/2019 (BRASIL, 2019) que propõe as Diretrizes Nacionais para a Formação Inicial de Professores da Educação Básica - DCN e a Base Nacional Comum para a Formação Inicial - BNC-Formação. 
Dessa forma, fica evidenciado o cenário de contradição ideológica, de uma visão de mundo capitalista que busca a fragmentação e a desconstrução do curso de Pedagogia, bem como de todos os direitos garantidos pelas políticas públicas educacionais ao longo dos anos. O que está implícito nesse documento, enquanto característica e instrumento do mercantilismo educacional, é o pragmatismo neotecnicista, uma vez que os princípios norteadores da formação inicial de professores se limitam à execução de práticas pedagógicas para alcançar os objetivos de conhecimento atrelados às competências e habilidades no processo de ensino-aprendizagem já formatados na BNCC.

Diante das rupturas e ataques pelos quais a educação brasileira vem passando, lembremo-nos de Gramsci (2007, p. 74) com o conceito de guerra de posição que "[...] não seria uma batalha frontal, mas de trincheiras, de estratégias", ou seja, de assédio. Segundo Mészáros (2008, p. 15), "O principal objetivo dos que resistem contra a sociedade mercantil, a alienação e a intolerância é a emancipação humana.”. Logo, a elevação da consciência da massa, na atualidade, tem na educação pública a gênese da transformação humana, política e social. Por isso,

[...] como forma de resistência e estratégia de enfretamento das ações nas políticas educacionais que fragilizam a formação de professores, se defende a necessidade da epistemologia da práxis, melhor dizendo, de uma teoria do conhecimento que seja referenciada pela práxis como fonte e limite do conhecimento, fundamentando o trabalho dos professores. (CURADO SILVA, 2019, p. 11).

Do ponto de vista da filosofia da práxis, as contradições e mediações implícitas na história do curso de Pedagogia no Brasil são salutares, já que há o entendimento pela busca da unidade teoria e prática que fortalece a possibilidade de oferta de formação inicial de professores com base nos fundamentos e princípios - defendidos pelo movimento dos educadores (as) e entidades nacionais - ancorados, dentre outras, nas concepções críticas do materialismo histórico dialético de Marx. Isso compreende uma proposta de formação inicial emancipadora com significativa relevância para o trabalho docente transformador. Não obstante, a proposta de formação inicial de professores, expressa pela Resolução CNE/CP n. 02/2019 (BRASIL, 2019), são impostos inúmeros desafios e, nesse sentido, a concepção de Mészáros (2008, p. 16) ratifica a complexidade desse contexto histórico ao afirmar que

No reino do capital, a educação é, ela mesma, uma mercadoria. Daí a crise do sistema público de ensino, pressionado pelas demandas do capital e pelo neoliberalismo, em que tudo se vende, tudo se compra, tudo tem preço, do que a mercantilização da educação. Uma sociedade que impede a emancipação só pode transformar os espaços 
educacionais em shopping centers, funcionais à sua lógica do consumo e do lucro.

Diante disso, convém destacar mais alguns elementos da complexa engrenagem desse sistema hegemônico e alienante com o que Silva (2020, p. 67) pontua acerca da sociedade capitalista que, sendo

[...] pautada em classes, sustentada pela desigualdade, o senso comum é instrumento de poder da classe dominante; é expressão da hegemonia dessa classe. É constituído marcadamente pela visão e interesses dos dominantes, por ideias desagregadas e não expressa uma concepção verdadeira e consciente da maioria da população. Sem se deixar perceber, a fatia detentora de poder e privilégios dissemina os seus interesses e determinados arranjos sociais, políticos e econômicos necessários a manutenção do status quo.

Destarte, percebemos o quanto os interesses da hegemonia dominante para perpetuar privilégios e poder estão objetivados na política de formação inicial e continuada de professores, assim como o estão na Base Nacional Comum Curricular. É sobre isso que discutiremos a seguir.

\section{A rigidez política e ideológica implícita na Resolução n. 02/2019}

A etimologia do conceito oriundo do latim respublica = coisa pública, ou seja, um governo do interesse de todos, independentemente da forma de governo, soa dogmático e contraditório em relação às proposições expressas na Resolução CNE/CP n. 2/2019, uma vez que a lei máxima do país defende a educação como direito para o pleno desenvolvimento da pessoa (BRASIL, 1988). A resolução traze elementos conceituais em sua essência, tais quais a universalidade e a abstração que são características do racionalismo do século XVIII, cuja premissa desconsidera as questões materiais e objetivas em que o sujeito vive e ratifica o subjetivismo secular sob a concepção do idealismo, isto é, educa-se para a utopia e a passividade.

Esse tipo de educação sustenta a BNC-Formação - que têm como objetivo a implantação da BNCC, instituída pelas Resoluções CNE/CP n. 2/2017 e CNE/CP n. 4/2018 - para normatizar e padronizar as competências e habilidades necessárias para a formação de professores com vistas à preparação, única e exclusivamente, para o mercado de trabalho, ou seja, mão de obra que atenda à lógica da reprodução capitalista. Tanto a BNC-Formação, a BNCC e as DCN para o curso de Pedagogia resgatam a Pedagogia das Competências e articulam o neotecnicismo ao mercantilismo educacional para atender 
demandas internas e externas do capital. São documentos que estão na contramão da concepção progressista de educação, do caráter humanista e emancipador que a educação deve ter por que "[...] o currículo formativo, para assimilar um conhecimento profissional básico, deve promover experiências interdisciplinares que permitam que o futuro professor possa integrar os conhecimentos e procedimentos diversos" (IMBERNÓM, 2011, p. 64) para sua formação e profissionalização.

Nessa proposta de formação, é imprescindível a busca da unidade formativa do trabalho docente no curso de Pedagogia, da diversidade de disciplinas a partir de uma concepção psicopedagógica - integração e relação do conhecimento didático do conteúdo com o conhecimento psicopedagógico; e isso requer o exercício constante de uma formação crítica pautada nas noções, atitudes e realidades educativas. A fim de ratificar essa concepção de formação ampla do curso de Pedagogia, bem como sua relevância social para a formação do futuro professor, ressaltamos que a atividade humana é uma prática transformadora para discentes e docentes e que

A teoria materialista de que os homens são produto das circunstâncias e da educação e de que, portanto, homens modificados são produto de circunstâncias diferentes e de educação modificada, esquece que as circunstâncias são modificadas precisamente pelos homens e que o próprio educador precisa ser educado. Leva, pois, forçosamente, à divisão da sociedade em duas partes, uma das quais se sobrepõe à sociedade [...]. A coincidência da modificação das circunstâncias e da atividade humana só pode ser apreendida e racionalmente compreendida como prática transformadora. (MESZÁROS, 2008, p. 20).

A prática transformadora para docentes e discentes, expressa na proposta de formação de professores da Resolução n. 2/2015, foi totalmente desconsiderada na Resolução n. 2/2019. Os pressupostos implícitos nessa resolução apresentam estratégias e uma nova proposta de formação inicial de professores/pedagogos vinculadas a um projeto de formação utilitarista que limita o trabalho docente aos requisitos do capital, transformando o professor em um técnico sob a concepção pragmática de formação. Além disso, Leão (1998, p. 43) esclarece que há

[...] dois fatores que ajudam a entender o porquê da ênfase dada pelas políticas educacionais à formação de professores. Como primeiro fator, o autor aponta a emergência de um novo paradigma de capacitação técnica, mais pragmática e, no entanto, pragmático e flexível, imposto pela reestruturação produtiva, ou seja, pela passagem do modo de acumulação capitalista fordista/keynesiana para a nova forma de regulação capitalista, intitulada de acumulação flexível. 
Sendo assim, entendemos que o projeto de formação de professores do curso de Pedagogia encontra-se num campo de disputa, uma vez que surgem alguns questionamentos, tais como "Que professor formar?"; "Qual o papel desse professor na formação dos sujeitos?"; "Para qual sociedade?”. A proposição de formação inicial e continuada de professores expressa na Resolução CNE/CP n. 2, de $1^{\circ}$ de julho de 2015 (BRASIL, 2015) foi constituída conforme os princípios da epistemologia da práxis, ou seja, vem ao encontro de não só tentar responder a tais questões, mas também de ampliar e tornar a base do curso de Pedagogia no Brasil mais sólida.

Além disso, é necessário evidenciar três princípios que formam o eixo para a formação de professores ancorada nas concepções críticas do materialismo histórico dialético, a saber: o trabalho docente, a relação teoria e prática e a emancipação humana. A epistemologia da práxis traz a unidade teoria/prática que se relaciona de forma dialética com os demais princípios, isto é, complementam-se e são indissociáveis porque compreender a relação teoria e prática significa enxergar o ser do trabalho docente que, no processo ensino-aprendizagem, constrói-se na humanidade que permeia a relação professor/aluno, bem como na possibilidade de emancipação do sujeito.

Portanto, torna-se imprescindível construir e estabelecer o entendimento de conceitos que estão no escopo da legislação para formação de professores, mais especificamente no curso de pedagogia, para que possamos tecer análises críticas, construtivas e transformadoras acerca da Resolução n. 2/2019. Na história da filosofia grega, viveu Platão, o pai do idealismo antigo, que escreveu a famosa metáfora do "mito da caverna" na qual havia dois mundos: o mundo sensível e o mundo inteligível. O primeiro afirma que o que se conhece são meras aparências, já que a experiência não é fonte segura para se conhecer, visto que se transforma como o devir. O segundo ratifica que a razão é a única fonte para se alcançar a verdade absoluta ou racional, isto é, as ideias encontram-se no plano da abstração imutável.

Neste sentido, a aparência das premissas da Resolução n. 2/2019 está no âmbito do mundo sensível, ou melhor, da experiência que o permeia e o vincula aos resultados da ascensão do lucro obtido pelo sistema capitalista que enxerga a educação como mercadoria, conforme Marx denominou: um mero objeto com "valor de troca"; evidenciando, assim, mais uma das estratégias da mais valia como um dos mecanismos do capitalismo. Já a essência nas entrelinhas desse documento, consubstancia o potencial transformador do trabalho docente em uma ferramenta de massificação e padronização do currículo, desconsiderando a diversidade educacional, cultural, social e econômica no país. 
Partindo das premissas construídas a partir do consenso coletivo das entidades educacionais nacionais e que resultou na elaboração da Resolução n. 2 , de $1^{\circ}$ de julho de 2015, fica evidente que a Resolução n. 2/2019 desconstrói e contraria todos os anseios e concepções de educação pautadas na gestão e na pesquisa que visam proporcionar uma formação de professores fundamentada na formação crítica e na produção de conhecimentos, aproveitando os espaços onde há a possibilidade de se concretizarem as relações educacionais. Logo, essas mudanças refletem necessariamente no processo de profissionalização docente, pois segundo Cruz (2017, p. 32),

\begin{abstract}
A profissão docente foi estabelecendo uma série de caracterizações e ações sob as quais os professores se definiriam como profissionais do ensino, a saber: i) exercício da atividade docente em tempo integral e como principal ocupação; ii) estabelecimento de um suporte legal para esse mesmo exercício, associado à; iii) criação de instituições específicas para a formação de professores e à; iv) participação em associações profissionais que desempenharam um papel fundamental na defesa do estatuto socioprofissional dos professores.
\end{abstract}

Além disso, sabe-se que a proposição da Resolução n. 2/2015 ratificava os fundamentos do curso de licenciatura em Pedagogia e postulava os requisitos imprescindíveis que estruturam o conceito de intelectual orgânico que se constitui

[...] como alguém capacitado para elaborar, de modo crítico e equilibrado, suas atividades manuais e físicas com sua atividade intelectual. E sua formação não se estabeleceria necessariamente nas cadeiras da academia, mas no encontro social e político estabelecido entre as pessoas nos mais diversos espaços destinados a "elevação cultural e moral", seja nos conselhos de fábrica, nos sindicatos, nas associações de bairro, no clube, no partido, nos debates públicos, nos grupos de discussão, etc. (GRAMSCI, 2002, p. 87).

Assim, entendemos que, para além dos muros da escola, há grande relevância na construção de orientações, princípios e fundamentos para a formação inicial e continuada de professores pela coletividade das instituições, entidades e sindicatos que representam e lutam pela educação pública, gratuita, laica, inclusiva e de qualidade referenciada socialmente. Torna-se, portanto, imprescindível restabelecer o diálogo entre o Ministério da Educação, o Conselho Nacional de Educação e a sociedade civil, a fim de buscar um consenso respaldado no compromisso e responsabilidade com a qualidade da educação pública. Para isso, a formação de professores no curso de Pedagogia no Brasil tem que ser constituída num cenário cuja diversidade cultural, social, econômica e política sejam os eixos norteadores do currículo, da gestão e da pesquisa. 


\section{Considerações}

Por meio das discussões propostas, qual a relevância de se pensar a educação pela práxis de forma crítica e transformadora, considerando as condições objetivas e materiais nas quais o processo de ensino-aprendizagem se constitui? Os elementos teóricos, que perpassam o artigo, estão relacionados ao materialismo histórico-dialético e consolidam o arcabouço teórico do ponto de vista teleológico e ontológico, cujo cerne é o desenvolvimento do ser social mediado pelo trabalho. Esse trabalho pressupõe a relação orgânica entre a própria natureza e o objeto resultante da transformação laboral.

Além disso, a formação de professores/pedagogos tem sua história e relevância na consolidação de uma educação pública de qualidade referenciada socialmente que pressupõe uma teoria do conhecimento alinhada com as seguintes premissas: a proposta deve-se iniciar na perspectiva reflexiva ao encontro do intelectual-reflexivo; não se limita somente à prática, mas busca a práxis; a escola pode ser um celeiro de pesquisa para o desenvolvimento do professor pesquisador; e, por fim, o trabalho deve-se vincular à práxis pedagógica (formação/prática docente). Contudo, a Resolução CNE/CP n. 2/2019 vai na contramão dessas premissas porque limita a formação inicial de professores aos preceitos e mecanismos do capital, isto é, transforma essa formação docente num instrumento pragmático utilitarista e a fragmenta, uma vez que desconsidera as idiossincrasias da diversidade brasileira, padronizando a formação inicial e continuada em todo país.

Por conseguinte, é preciso "esperançar" e resistir contra a flexibilização do capital e suas respectivas estratégias reprodutivas de paradigmas personificados em ideologias que manipulam a classe subalterna a fim de aliená-la. Nas concepções de Marx, Gramsci e Lukács, no entanto, a revolução encontra-se na própria essência do capital, ou seja, as crises e contradições históricas (devir = mudança) desse sistema são as portas para a emancipação humana e a transformação do modelo de sociedade atual.

Nesse sentido, a formação de professores/pedagogos requer o compromisso político, ético e moral tanto das instituições formadoras quanto dos sujeitos que almejam ser docentes, porque educar é um ato político, é transformação e emancipação de quem ensina e de quem aprende. Essa educação que almejamos pode se concretizar pela constituição da unidade teoria/prática da práxis transformadora que implica na mudança da subjetividade e objetividade, já que é mediada pelas relações sociais, históricas, culturais e econômicas para nos constituir sujeitos históricos que somos. 
Curso de Pedagogia no Brasil: Algumas discussões sobre as políticas de formação

\section{Referências}

BRASIL. Constituição da República Federativa do Brasil. Brasília: CDI, 1988. Disponível em: https://www2.camara.leg.br/legin/fed/consti/1988/constituicao-1988-5outubro-1988-322142-publicacaooriginal-1-pl.html. Acesso em: 13 dez. 2020.

BRASIL. Resolução $n$. 2, de $1^{o}$ de julho de 2015. Disponível em: http://portal.mec.gov.br/docman/agosto-2017. Acesso em: 13 dez. 2020.

BRASIL. Resolução CNE/CP n. 2, de 22 de dezembro de 2017. Disponível em: http://basenacionalcomum.mec.gov.br/images/historico/RESOLUCAOCNE_CP222DE DEZEMBRODE2017.pdf. Acesso em: 13 dez. 2020.

BRASIL. Resolução CNE/CP n. 4, de 17 de dezembro de 2018. Disponível em: http://portal.mec.gov.br/docman/dezembro-2018-pdf/104101-rcp004-18/file. $\quad$ Acesso em: 13 dez. 2020.

BRASIL. Resolução CNE/CP n. 2, de 20 de dezembro de 2019. Disponível em: http://portal.mec.gov.br/docman/dezembro-2019. Acesso em: 13 dez. 2020.

CRUZ, Shirleide Pereira da Silva. Professor polivalente: profissionalidade docente em análise. Curitiba: Appris, 2017.

CURADO SILVA, Kátia Augusta Pinheiro Cordeiro. Epistemologia da práxis na formação de professores: perspectiva crítico-emancipadora. Campinas: Mercado das Letras, 2019.

EVANGELISTA, Olinda; SEKI, Allan Kenji; SOUZA, Artur Gomes de. O crescimento perverso das licenciaturas privadas. In: EVANGELISTA, Olinda et al. Desventuras dos professores na formação para o capital. Campinas: Mercado de Letras, 2019.

GRAMSCI, Antonio. Cadernos do cárcere: introdução ao estudo da filosofia e a filosofia de Benedetto Croce. 2. ed. Rio de Janeiro: Civilização Brasileira, 2001. Vol. 1

GRAMSCI, Antonio. Cadernos do cárcere: o Risorgimento, notas sobre a história da Itália. Rio de Janeiro: Civilização Brasileira, 2002. Vol. 5.

GRAMSCI, Antonio. Cadernos do cárcere: temas de cultura: ação católica: americanismo e fordismo. Rio de Janeiro: Civilização Brasileira, 2007, 2.ed. Vol. 4.

IMBERNÓN, Franscisco. Formação docente e profissional: formar-se para a mudança e a incerteza. São Paulo: Cortez, 2011.

LEÃO, Geraldo Magela Pereira. Gestão da educação e qualificação docente: algumas reflexões em torno da formação permanente de professores/as. Revista Educação e Realidade, Porto Alegre, n. 1, vol. 23, p. 43-56, jan./jun. 2016.

LUKÁCS, Gyorgy. Para uma ontologia do ser social I. São Paulo: Boitempo, 2018. 
MARX, Karl. O Capital. São Paulo: Nova Cultural Ltda., 1985. Vol. II. (Série Os Economistas).

MARX, Karl. O Capital-crítica de economia política-livro primeiro: o processo de produção do capital. 17. Ed. Rio de Janeiro: Civilização Brasileira, 1999. Vol. 1.

MÉSZÁROS, Isteván. A educação para além do capital. São Paulo: Boitempo, 2008.

NETTO, José Paulo. Ditadura e Serviço Social: uma análise do Serviço Social no Brasil pós-64. 17. ed. São Paulo: Cortez, 2015.

SAVIANI, Dermeval. Histórias das ideias pedagógicas no Brasil. Campinas: Autores Associados, 2019.

SILVA, Deise Rosalio. O lugar da educação em Gramsci. Curitiba: Appris, 2020.

$* * *$

Recebido em: 23 jan. 2021. Aprovado em: 13 jul. 2021.

*Miro de Souza Almeida é professor da Secretaria de Estado de Educação do Distrito Federal com graduação em Filosofia e Pedagogia, e pós-graduação Lato Sensu em Formação de tutores em EaD. É membro do Grupo de Estudos e Pesquisas sobre Formação e Atuação de Professores/Pedagogos-GEPFAPe.

E-mail: miroalmeida@gmail.com

ORCID: https://orcid.org/0000-0003-1481-7030

**Maria Eneida da Silva é docente da Universidade Estadual de Goiás - UEG. É Doutoranda em Educação pela UnB e Mestre em Educação, Linguagem e Tecnologias pela UEG. É pesquisadora do Grupo de Estudos e Pesquisas sobre Formação e Atuação de Professores/Pedagogos-GEPFAPe e do Grupo de Estudos em Formação de Professores e Interdisciplinaridade-GEFOPI. Coordenadora Estadual da Anfope-Goiás.

E-mail: eneida.silva@ueg.br

ORCID: https://orcid.org/0000-0003-2788-032X

***Andréa Kochhann é docente do Programa de Pós-Graduação em Gestão, Educação e Tecnologias da Universidade Estadual de Goiás, Doutora em Educação pela UnB e Mestre em Educação pela PUC/GO. É pesquisadora e coordenadora o Grupo de Estudos em Formação de Professores e Interdisciplinaridade-GEFOPI e pesquisadora do Grupo de Estudos e Pesquisas sobre Formação e Atuação de Professores/Pedagogos-GEPFAPe.

E-mail: andreakochhann@yahoo.com.br

ORCID: https://orcid.org/0000-0001-6852-073X 